\title{
Improving frequency stability in low inertia power systems using synthetic inertia from wind turbines
}

DOI:

10.1109/PTC.2017.7980836

\section{Document Version}

Accepted author manuscript

Link to publication record in Manchester Research Explorer

\section{Citation for published version (APA):}

Gao, Q., \& Preece, R. (2017). Improving frequency stability in low inertia power systems using synthetic inertia from wind turbines. In IEEE PowerTech Manchester $2017 \mathrm{https}: / /$ doi.org/10.1109/PTC.2017.7980836

\section{Published in:}

IEEE PowerTech Manchester 2017

\section{Citing this paper}

Please note that where the full-text provided on Manchester Research Explorer is the Author Accepted Manuscript or Proof version this may differ from the final Published version. If citing, it is advised that you check and use the publisher's definitive version.

\section{General rights}

Copyright and moral rights for the publications made accessible in the Research Explorer are retained by the authors and/or other copyright owners and it is a condition of accessing publications that users recognise and abide by the legal requirements associated with these rights.

\section{Takedown policy}

If you believe that this document breaches copyright please refer to the University of Manchester's Takedown Procedures [http://man.ac.uk/04Y6Bo] or contact uml.scholarlycommunications@manchester.ac.uk providing relevant details, so we can investigate your claim.

\section{OPEN ACCESS}




\title{
Improving Frequency Stability in Low Inertia Power Systems Using Synthetic Inertia from Wind Turbines
}

\author{
Qunce Gao, Robin Preece \\ School of Electrical and Electronic Engineering \\ The University of Manchester \\ Manchester, United Kingdom \\ robin.preece@manchester.ac.uk
}

\begin{abstract}
In response to ongoing worldwide theme of sustainable development, more and more fossil energy based conventional synchronous generators are being replaced by renewable energy sources for the electricity production in modern power systems. However, some low inertia issues will be brought into future power systems, which will not be conducive to system frequency stability. This paper aims at improving frequency stability in low inertia power systems by using synthetic inertia from DFIG based wind turbines. All simulation work involved in this paper is performed on the software platform MATLAB/SIMULINK. The test model is chosen to be a power system connected by an integrated DFIG based wind farm. After modification and validation the chosen test model will be applied to simulate the GB equivalent large system model. It can be eventually verified that the impacts of synthetic inertia from wind turbines will become more significant on system frequency stability in terms of both ROCOF and frequency nadir when more wind farms are being integrated into future low inertia GB power system.
\end{abstract}

Index Terms-DFIG based wind turbine, frequency stability, rate of change of frequency (ROCOF), synthetic inertia.

\section{INTRODUCTION}

In order to meet the targets of carbon emission reduction and cater for the worldwide theme of sustainable development, many countries around the world have already taken actions to integrate more and more renewable energy sources, especially wind turbines, into the power system to replace some fossil energy based conventional synchronous generating units. In 2009 , the EU has adopted a renewable energy related directive to pledge that about 33\% electrical power generation will be provided by renewable energy sources by 2030 and further to $100 \%$ electrical power generation by 2050 [1]. A survey report states that the German Energy Agency plans to install up to 52.5 GW wind farms into the German grid for electrical power generation by the end of 2020, and among about 20.4 GW electrical power generation will be contributed by the offshore wind farms [2]. Moreover, it is predicted that $30 \%$ to $45 \%$ of the total electrical power generation in UK will come from the renewable generation by 2030 according to the UK renewable energy roadmap, and up to $40 \mathrm{GW}$ offshore wind turbines will be installed by the end of 2030 [3].
However, some low inertia issues will be brought into the future power system due to the rapidly increasing penetration of renewable energy generation, which is not conducive to system frequency stability. One the one hand, the inertia of renewable generator is relatively smaller than the inertia of conventional synchronous generator. Therefore, the total system inertia will be reduced as a result of gradual replacement of the conventional synchronous generators. One the other hand, the commonly used renewable energy sources are connected to the main ac grid by means of some power electronic interfaces, which will inherently decouple the inertia of renewable generators form the main ac grid. Therefore, if without additional controls, almost no inertial contribution from renewable energy sources could be provided for system frequency stability, which will further reduce the total system inertia and eventually lead to future low inertia power systems [4], [5]. Based on the swing equation, within instants of a sudden disturbance, rate of change of frequency (ROCOF) will be inversely proportional to the total system inertia [6]. However, ROCOF in low inertia power systems will be so fast that power systems might collapse prior to responses of primary frequency control. Due to lack of adequate system inertia, power system cannot react to sudden disturbances promptly, which might cause some serious cascading failures [7].

In order to address the potential low inertia issues in future power systems, some frequency control strategies have been proposed in industry to emulate the so called synthetic inertia from various renewable energy sources, such as variable speed wind turbines.

A control strategy was found in [8] aiming at adding some supplementary control loops to enable the Doubly-Fed Induction Generator (DFIG) based wind farms to perform similar to the conventional synchronous generators by releasing stored kinetic energy from the rotating masses of wind turbines. The authors in [9] also stated that power system stability could be improved by participating the wind farms with the control functionality into primary and secondary frequency controls to provide the inertial responses. In terms of provision of primary control reserves, the capabilities of the DFIG based wind turbines as well as the full converter based wind turbines were investigated in [10] and [11] separately. In order to improve the system frequency responses 
after sudden disturbances, three control strategies were proposed by authors in [12] aiming at participating the wind turbines into the system frequency control. Moreover, the research in [13] proposed three activation schemes which were adopted for the application of synthetic inertia control on the full converter based wind turbines. It was found in [14] that the maximum limit of the synthetic inertial power provided by wind turbines was $5 \%-10 \%$ of the pre-event power. In order to figure out how much stored kinetic energy could be extracted from the wind turbines, a probabilistic method was used by authors in [15]

The main concern for the synthetic inertia emulation from wind turbines is the measurement noises of system frequency, since performances of synthetic inertia controller are dominated by the input signal of ROCOF. Furthermore, the stored kinetic energy from wind turbines cannot be extracted too much in order to avoid stalling of the turbine rotor.

Overall, based on the aforementioned literatures related to the synthetic inertia emulation, synthetic inertia emulation from the DFIG based wind turbines can be regarded as a promising technique to assist with primary frequency control in future low inertia power systems. Therefore, this paper aims at improving frequency stability in low inertia power systems using synthetic inertia from DFIG based wind turbines. The major contributions of this paper are as follows:

- Development and validation of the simplified DFIG based wind farm model for synthetic inertia studies.

- Assessment of the impacts of noise and filtering on the performances of synthetic inertia controller.

- Application of synthetic inertia on future GB system models.

\section{OVERVIEW OF TEST MODEL AND SYNTHETIC INERTIA CONTROLLER}

\section{A. Test Model Description}

A power system connected by a six $1.5 \mathrm{MW}$ wind turbines integrated DFIG based wind farm is chosen as the test model, which is selected from one of the SimPowerSystems Demos called Wind Farm (DFIG Phasor Model) in MATLAB. The simplified structure of chosen test model is illustrated in Fig. 1. The chosen test model is mainly consisted of three parts: the main AC grid represented by a $120 \mathrm{kV}$ voltage source is on the left, two transformers, $25 \mathrm{kV}$ distribution feeders as well as load connect a 9 MW DFIG based wind farm on the right.

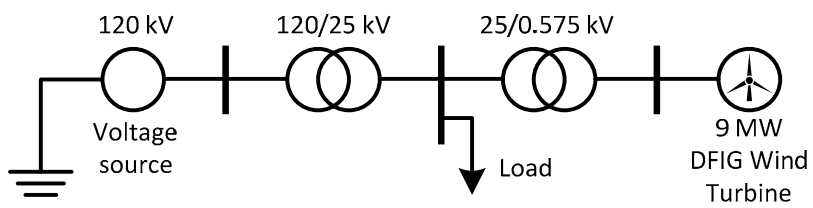

Fig. 1. Simplified model of test system

The chosen test model is initially simulated using phasor type, which means the system frequency is specified as a fixed value (60 Hz for the US system). Therefore, actual changes of system frequency cannot be directly detected. Since ROCOF is vital for application of synthetic inertia, the $120 \mathrm{kV}$ voltage source will be combined with an additional governor controller to perform like a conventional synchronous generator for the measurement of system frequency changes after sudden disturbances.

The inherent characteristics of DFIG based wind turbines determine that almost no inertial power could be provided to compensate active power imbalances after sudden imbalances. Thus, in order to control electrical power output from wind farm, the control loops of electrical power reference $\left(P_{e}^{\text {ref }}\right)$ in DFIG based wind farm model are partly illustrated in Fig. 2. $K_{P}$ and $K_{I}$ represent proportional and integral gains, and $i_{q}^{\text {ref }}$ is the $q$-axis current reference for the inner current control. The additional synthetic inertial power that should be provided from the output of synthetic inertia controller for frequency control is represented by the signal $\Delta P$.

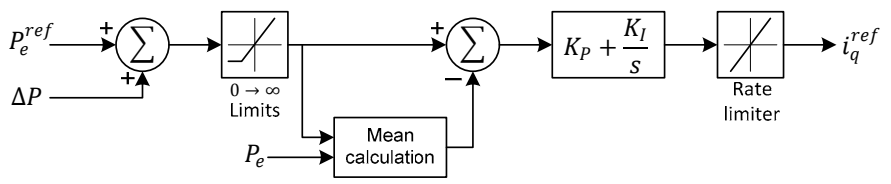

Fig. 2. The control loops of the electrical power reference.

\section{B. Synthetic Inertia Controller}

The system inertia $\left(H_{s y s}\right)$ can be quantified by the amount of kinetic energy stored in the rotating masses of conventional synchronous generators as well as some motors that are directly connected to the main ac grid using (1) [6].

$$
H_{\text {sys }}=\frac{K E}{S_{\text {Rating }}}
$$

In (1), KE represents kinetic energy stored in power system $(\mathrm{MJ})$, and $S_{\text {Rating }}$ represents machine rating (MVA).

As aforementioned in Chapter I, within instants of a sudden disturbance, ROCOF will be initially determined by total system inertia. This relationship can be represented using the swing equation as shown in (2) [6].

$$
\frac{d f}{d t}=\frac{f_{n}}{2 H}\left(P_{m}^{p u}-P_{e}^{p u}\right)
$$

In (2), $\frac{d f}{d t}$ represents rate of change of frequency in $\mathrm{Hz} / \mathrm{s}, f_{n}$ is nominal frequency in $\mathrm{Hz}, H$ is inertia constant of system in $\mathrm{s}, P_{m}^{p u}$ is mechanical power in per-unit, and $P_{e}^{p u}$ is electrical power in per-unit.

As shown in (2), within the first few seconds after sudden disturbances, the active power imbalance between mechanical power and electrical power can be assumed to be temporarily fixed, and nominal system frequency is constant as well. Thus, initial ROCOF will be inversely proportional to the total system inertia. The larger total system inertia is, the slower ROCOF will be. A power system with larger system inertia can gain more time for the subsequent generator governor control actions and avoid unnecessary under-frequency load shedding. 


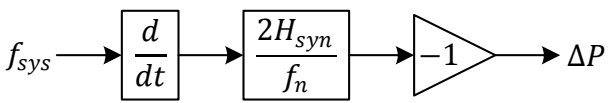

Fig. 3. The structure of the synthetic inertia controller.

The mechanism of synthetic inertia control is to generate an additional power $(\Delta P)$ to compensate the active power imbalance after sudden disturbances by detecting changes of power system frequency. Therefore, based on the swing equation in (2), the structure of synthetic inertia controller is illustrated in Fig. 3, in which $f_{\text {sys }}$ is the measured system frequency.

$H_{\text {syn }}$ represents synthetic inertia constant of the controller. It should be noted that synthetic inertia controller will perform in the opposite way if the minus one represented by a gain block is not added to synthetic inertia controller. For example, if total demand is greater than total generation, frequency will drop leading to a negative value of ROCOF, and synthetic inertial power $(\Delta P)$ from output of synthetic inertia controller will be positive. As shown in Fig. 2, this positive synthetic inertia power $(\Delta P)$ will be added into the scheduled electrical power reference, which will increase the electrical power output from wind farm to compensate the active power imbalances. The operation of synthetic inertia controller will kick in before primary frequency control to slow down ROCOF, which is similar to performances of natural system inertia by releasing stored kinetic energy from rotating masses of machines.

\section{TEST MODEL SIMPLIFICATION AND VALIDATION}

\section{A. Development of Simplified DFIG based Wind Farm Model}

In order to be applied for simulation of large system, original DFIG based wind farm model need to be further simplified to reduce its complexity and shorten its simulation time. Impacts of variations in wind speed are not considered for simplification. A steady state electrical power output $\left(P_{e}^{S S}\right)$ of $0.1847 \mathrm{pu}\left(S_{B}\right.$ is 10 MVA) can be obtained from wind farm when wind speed is assumed to be fixed at $8 \mathrm{~m} / \mathrm{s}$ based on scheduled power-speed characteristic. Furthermore, the chosen fixed wind speed $(8 \mathrm{~m} / \mathrm{s})$ is below the rated wind speed $(12 \mathrm{~m} / \mathrm{s})$ so that pitch control is not considered.

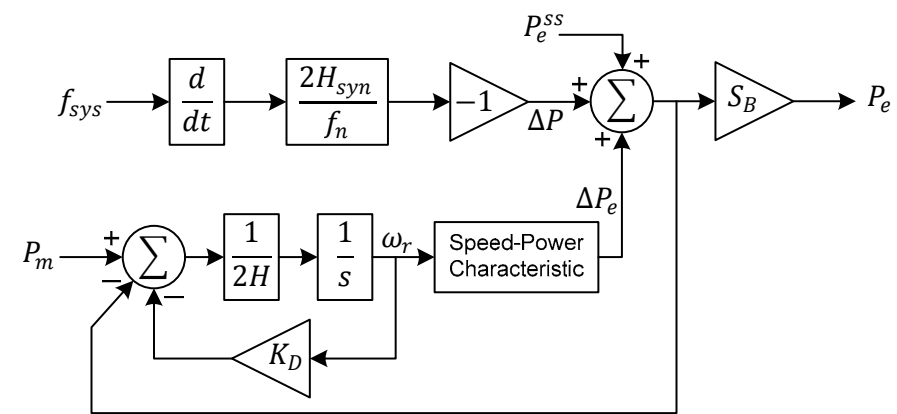

Fig. 4. The structure of the simplified DFIG-based wind power plant model.

As shown in Fig. 4, simplified DFIG based wind farm model is developed according to power relationship represented by (3).

$$
P_{e}^{S S}+\Delta P+\Delta P_{e}=P_{e}
$$

In (3), $P_{e}^{S S}$ is initial steady state electrical power output due to a fixed wind speed, $\Delta P$ is synthetic inertial power output from the synthetic inertia controller, $\Delta P_{e}$ is turbine rotor speed related electrical power changes according to power-speed characteristic and the rotor swing equation (including rotor damping $K_{D} \omega_{r}$ ), and $P_{e}$ is electrical power output from DFIG based wind farm.

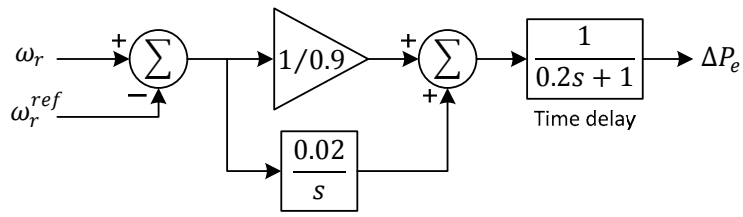

Fig. 5. The structure of the speed-power characteristic.

Detailed structure of speed-power characteristic controller is illustrated in Fig. 5. For a fixed wind speed of $8 \mathrm{~m} / \mathrm{s}$, the optimal turbine rotor speed $\left(\omega_{\mathrm{r}}\right)$ is $0.8 \mathrm{pu}$ as a reference. The variations in rotor speed will slightly influence electrical power output from wind turbine. For example, if $\omega_{\mathrm{r}}$ is smaller than its reference, $\Delta P_{e}$ will become negative, leading to the decrease of electrical power. Both primary and secondary controls are adopted in controller. Moreover, a time delay with a time constant of $0.2 \mathrm{~s}$ is added into the controller in order to make its physical meaning of speed power characteristic more realistic.

\section{B. Validation of Simplified DFIG based Wind Farm Model}

As shown in Fig. 6, the correctness of simplification can be validated by comparing similarity of electrical power responses between original DFIG model and simplified DFIG model using RMSE values. By calculation, RMSE value of electrical power responses between the original DFIG model and the simplified DFIG model is about 0.008 , which can verify the correctness of model simplification.

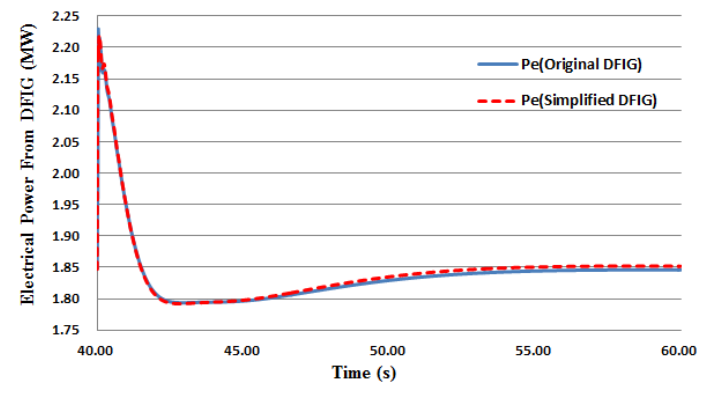

Fig. 6. The Comparison of Electrical Power Responses from DFIG Models.

\section{ANALYSIS AND DISCUSSION}

\section{A. Impacts of Synthetic Inertia Constant on Frequency}

Based on simplified DFIG model, the impacts of variations in synthetic inertia constant $\left(\mathrm{H}_{\text {syn }}\right)$ on synthetic inertial power from synthetic inertia controller are illustrated in Fig. 7. By adopting controlling variable method, $\mathrm{H}_{\text {syn }}$ is varied from $1 \mathrm{~s}$ to $13 \mathrm{~s}$ at an interval of $4 \mathrm{~s}$ when a sudden load increase of $0.15 \mathrm{pu}$ occurs at $40 \mathrm{~s}$. The larger synthetic inertia constant is, the more synthetic inertial power can be obtained. Larger $\mathrm{H}_{\text {syn }}$ could generate more synthetic inertial power to compensate active power imbalances 
after the disturbances, which will slow down ROCOF. A slower ROCOF will result in a higher frequency nadir. As expected in Fig. 8, when $\mathrm{H}_{\text {syn }}$ increases from $1 \mathrm{~s}$ to $13 \mathrm{~s}$, the frequency nadir will be increased by about $0.05 \%$ from $59.71 \mathrm{~Hz}$ to $59.74 \mathrm{~Hz}$ and the ROCOF will be slowed down by about $48 \%$ from $0.36 \mathrm{~Hz} / \mathrm{s}$ to $0.19 \mathrm{~Hz} / \mathrm{s}$. Larger $\mathrm{H}_{\text {syn }}$ is more beneficial to system frequency stability in terms of both frequency nadir and ROCOF. However, impacts of variations in synthetic inertia constant on ROCOF are more significant than that on frequency nadir. Furthermore, with the synthetic inertia constant increasing, both the changing rates of ROCOF and frequency nadir will be slowed down.

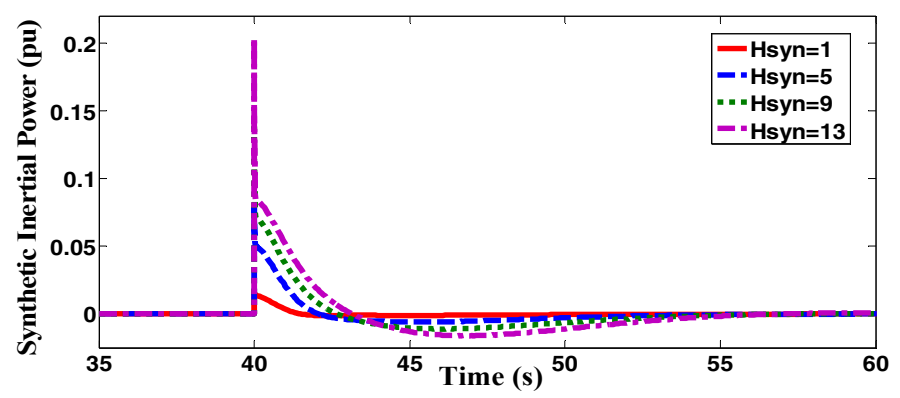

Fig. 7. The Impacts of Synthetic Inertia Constant on Synthetic Inertial Power.

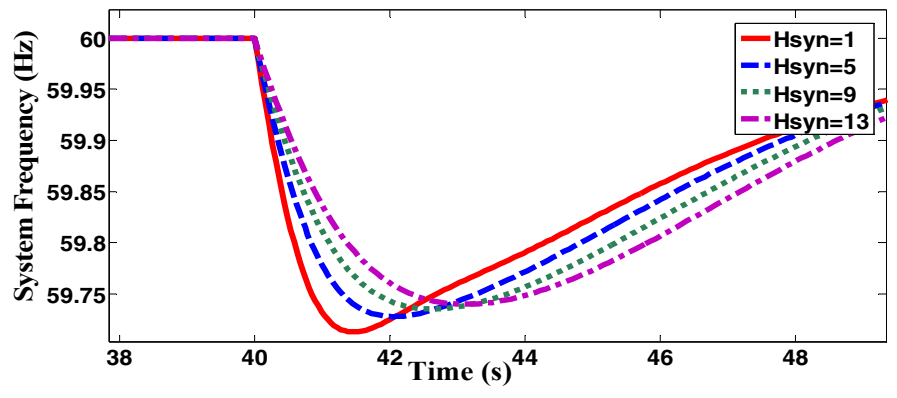

Fig. 8. The Impacts of Synthetic Inertia Constant on Frequency Responses.

\section{B. Impacts of Noise and Filtering on Frequency}

More concerns will focus on impacts of noise and filtering on system frequency responses. Since measured system frequency are always contaminated by noises from measurement devices, and appropriate filter is required to minimize noises as much as possible. The simulated results of impacts of noise and filtering on frequency nadir and ROCOF are summarized in Table I and Table II respectively.

The signal to noise ratio (SNR) is varied with $75.5 \mathrm{~dB}$, $85.5 \mathrm{~dB}, 95.5 \mathrm{~dB}, 105.5 \mathrm{~dB}$ and infinity successively. Meantime, time constant $(\mathrm{T})$ of first order filter is varied with $0.02 \mathrm{~s}, 0.05 \mathrm{~s}$, $0.1 \mathrm{~s}, 0.2 \mathrm{~s}, 0.5 \mathrm{~s}$ and $1 \mathrm{~s}$ in sequence. In addition, for all cases, synthetic inertia constant and load change disturbance are all kept same.

As shown in Table I, when the SNR is fixed, by increasing T, frequency nadir will firstly rise to a peak value when $\mathrm{T}$ is $0.5 \mathrm{~s}$, and then begin to drop. Comparing the best case with the worst case when SNR is infinity, frequency nadir can be increased by about $0.02 \%$. If when $\mathrm{T}$ is fixed, a higher frequency nadir will be obtained with a larger SNR. Comparing the best case with the worst case when $\mathrm{T}$ is $0.5 \mathrm{~s}$, frequency nadir will be increased by about $0.0004 \%$. Thus, impacts of variations in time constant (T) on frequency nadir are more significant compared with impacts of variations in SNR on frequency nadir.

As shown in Table II, when the SNR is fixed, by increasing T, ROCOF will become faster. Comparing the best case with the worst case when SNR is infinity, ROCOF can be slowed down by about $14 \%$. If $\mathrm{T}$ is fixed, a slower ROCOF will be obtained with a smaller SNR. Comparing the best case with the worst case when $\mathrm{T}$ is $0.5 \mathrm{~s}$, ROCOF can be slowed down by about $0.17 \%$. Thus, impacts of variations in time constant (T) on ROCOF are more significant compared with impacts of variations in SNR on ROCOF.

TABLE I. THE IMPACTS OF NOISE AND FILTERING ON FREQUENCY NADIR

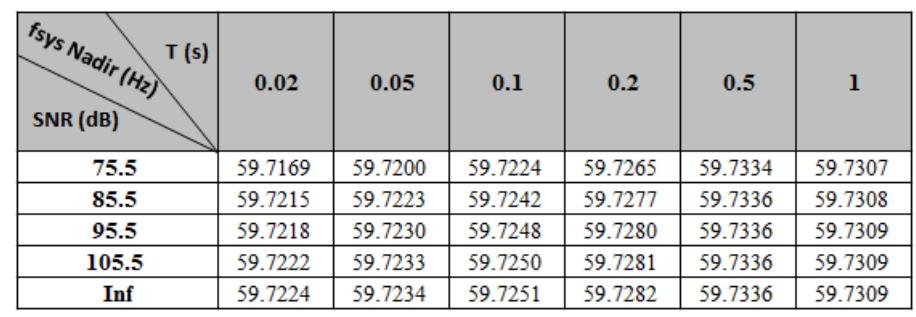

TABLE II. THE IMPACTS OF NOISE AND FILTERING ON ROCOF

\begin{tabular}{|c|c|c|c|c|c|c|}
\hline SNR (dB) & 0.02 & 0.05 & 0.1 & 0.2 & 0.5 & 1 \\
\hline 75.5 & -0.2796 & -0.3080 & -0.3140 & -0.3267 & -0.3502 & -0.3649 \\
\hline 85.5 & -0.3189 & -0.3123 & -0.3176 & -0.3288 & -0.3506 & -0.3648 \\
\hline 95.5 & -0.3100 & -0.3137 & -0.3187 & -0.3295 & -0.3507 & -0.3648 \\
\hline 105.5 & -0.3115 & -0.3141 & -0.3190 & -0.3296 & -0.3507 & -0.3648 \\
\hline Inf & -0.3123 & -0.3142 & -0.3192 & -0.3298 & -0.3508 & -0.3648 \\
\hline
\end{tabular}

TABLE III. THE IMPACTS OF NOISE AND FILTERING ON SyNTHETIC INERTIAL POWER PEAK

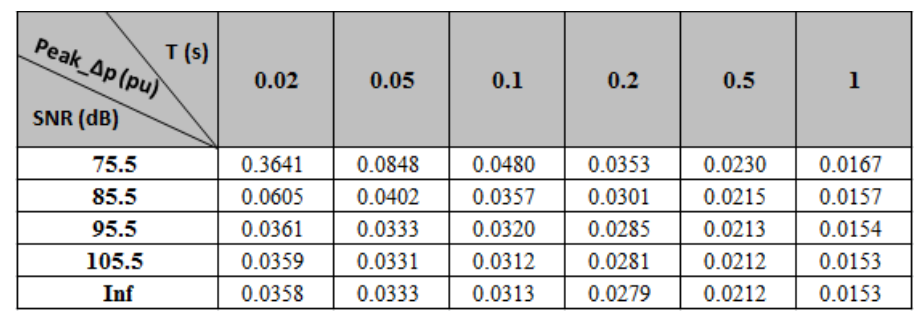

However, it is counterintuitive to observe that smaller SNR or more noise will result in slower ROCOF in Table II. This phenomenon can be further explained with the help of simulated results of synthetic inertial power peak (peak of $\Delta P$ ) as shown in Table III. It is supposed that the actual frequency signal will be superposed by the amplitude of random noise signal. Therefore, in this case when $\mathrm{T}$ is fixed, it is inferred that a smaller SNR with higher noise amplitude can increase the synthetic inertial power, which can be verified by the simulated results in Table III. More 
synthetic inertial power could be then used to compensate active power imbalances within instants after sudden disturbances, which will slow down the ROCOF accordingly.

Based on the aforementioned simulated results, a relatively larger time constant (T) and a larger SNR will be beneficial to system frequency stability in terms of frequency nadir. Whereas, a smaller time constant (T) and a smaller SNR will contribute better to frequency stability in terms of ROCOF. Thus, there is a trade-off between the control of frequency nadir and the control of ROCOF. Since ROCOF is vital for application of synthetic inertia controller, more concerns should be focused on control of ROCOF. In this paper, it is suggested that a relatively faster filter should be adopted. As for the noise issues, the improvement of ROCOF caused by random noise might occur occasionally, and simulated results in this experiment might not be replicated. For practical application of synthetic inertia controller, measurement noises of frequency responses should be minimized as much as possible for stable operation of synthetic inertia controller.

\section{APPLICATION ON GB EQUiVALENT LARGE Systems}

The simplified test model will be further applied to simulate the GB equivalent large systems in order to assess the impacts of synthetic inertia from wind turbines on frequency stability. For the year 2015, the capacity of total system generation in UK is assumed to be $25 \mathrm{GW}$ (at a light loading condition), and the capacity of wind generation accounts for about 8\% (2 GW) of the total system generation [16], [17]. As shown in Fig. 9, the year 2015 GB equivalent system model is developed according to the power relationship represented by (4).

$$
n_{W F} P_{e}^{W F}+P_{e}^{G e n}=P_{e}^{\text {load }}
$$

In (4), $n_{W F}$ is the number of wind turbines, $P_{e}^{W F}$ the power output from each turbine, $P_{e}^{G e n}$ is electrical power from all generating units, and $P_{e}^{\text {load }}$ is load demand power.

$H_{\text {syn }}$ in the synthetic inertia controller is assumed to be $200 \mathrm{~s}$ in order to cope with relatively slow ROCOF for year 2015 GB system. Based on total generation capacity of year 2015, transfer function of rotating mass and load model is assumed as $\frac{1}{15120 s+375}$ [16]. Moreover, the nominal system frequency for GB system is changed to be $50 \mathrm{~Hz}$. For simplification, the impacts of noise and filtering on system frequency are not considered in this model.

A sudden load increase $(1000 \mathrm{MW})$ is triggered at $10 \mathrm{~s}$. By varying percentage of wind farms that provide synthetic inertia control, simulated frequency responses are illustrated in Fig. 10.

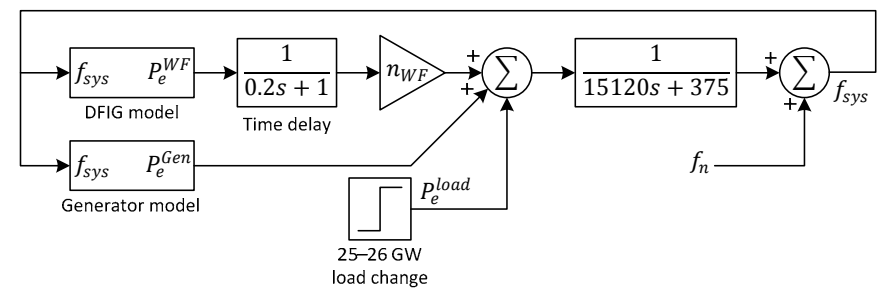

Fig. 9. The structure of 2015 GB equivalent system model.

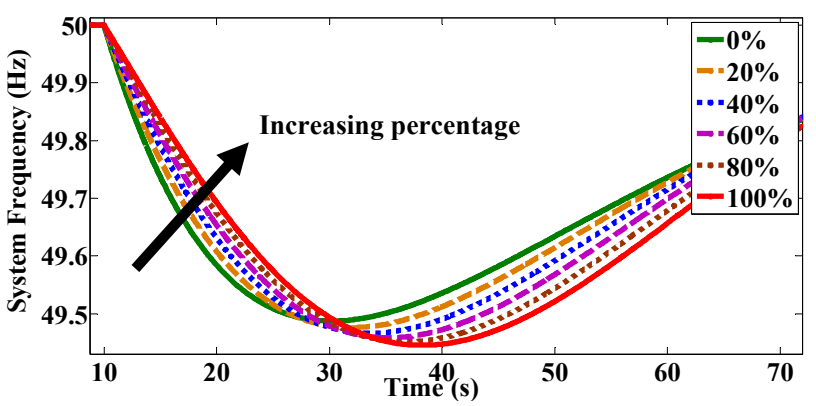

Fig. 10. The impacts of percentage of wind farms on frequency responses.

Assuming all wind farms are equipped with synthetic inertia controller, by increasing percentage of wind farms supporting the system frequency control from $0 \%$ to $100 \%$ at an interval of $20 \%$, ROCOF will become slower, but frequency nadir will be lower. Comparing ' $100 \%$ case' with ' $0 \%$ case', ROCOF can be slowed down by about $50 \%$ from $0.06 \mathrm{~Hz} / \mathrm{s}$ to $0.03 \mathrm{~Hz} / \mathrm{s}$, whereas frequency nadir will be decreased by about $0.08 \%$ from $49.49 \mathrm{~Hz}$ to $49.45 \mathrm{~Hz}$. There will be a trade-off between improvement of ROCOF and deterioration of frequency nadir. It is obvious to see that impacts of variation in percentage of wind farms on ROCOF are more significant than that on frequency nadir. Overall, synthetic inertia from wind turbines can effectively improve GB system frequency stability in terms of ROCOF.

It is counterintuitive to find that the increasing percentage of wind farm synthetic inertial supports will decrease the frequency nadir, which is contradictory to simulated results shown in Fig. 8. This unexpected phenomenon can be explained by considering Fig. 11. ROCOF will be negative leading to positive synthetic inertial power as shown by green curve, until the time at which the frequency nadir is reached. A sustained frequency deviation may result in a long period of frequency support from the wind turbines. However, the extraction of stored power from the wind turbines cannot be sustained for such a long time as it results in a reduction in the turbine rotor speed. Once the rotor speed reaches its nadir, the wind turbine will try to recover its rotor speed by extracting power from system and will appear as an additional load. If the rotor speed nadir occurs before the system frequency nadir, then additional load will appear on the network, resulting in a lower system frequency nadir. The larger percentage of wind farms is, the larger additional load will be. Thus, by increasing percentage of wind farms, frequency nadir will be slightly lower.

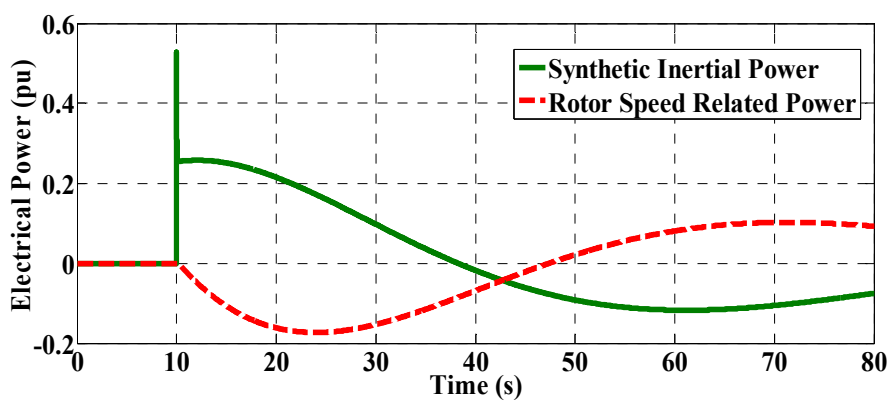

Fig. 11. The changes of electrical power in DFIG model for ' $100 \%$ case'. 
A potential solution to solve frequency nadir related issues is to incorporate pitch angle control with synthetic inertia control in order to extract more power from wind turbine during frequency recovery process. In addition, due to the operation of synthetic inertia controller, and its ability to reduce the system ROCOF, governor primary control will be impacted. Therefore, parameter tuning of system governors may need to be performed in order to improve the overall system frequency nadir.

Based on [18], it is predicted that wind farms in UK can provide about $30 \%$ of the total system generation by 2025 . Thus, assuming the capacity of total generation in 2025 is still 25000 MW, the wind power capacity will become $7500 \mathrm{MW}$. Due to the replacement of conventional generating units by wind farms, the total GB system inertia will be decreased, and the transfer function of rotating mass and load is assumed to be $\frac{1}{10584 s+375}$ [16]. It is assumed that all other parameters used in the year $2025 \mathrm{~GB}$ model are same with the year $2015 \mathrm{~GB}$ model. By varying the percentage of wind farms with $0 \%, 50 \%$ and $100 \%$, simulated frequency responses are illustrated in Fig. 12. By comparing the ' $100 \%$ case' with the ' $0 \%$ case', ROCOF can be slowed down by about $84 \%$ from $0.09 \mathrm{~Hz} / \mathrm{s}$ to $0.01 \mathrm{~Hz} / \mathrm{s}$, whereas frequency nadir will be decreased by about $0.17 \%$ from $49.46 \mathrm{~Hz}$ to $49.37 \mathrm{~Hz}$.

It can be concluded that the impacts of synthetic inertia from wind turbines will become more significant on system frequency stability in terms of both ROCOF and frequency nadir when more wind farms are being integrated into the future low inertia GB power system.

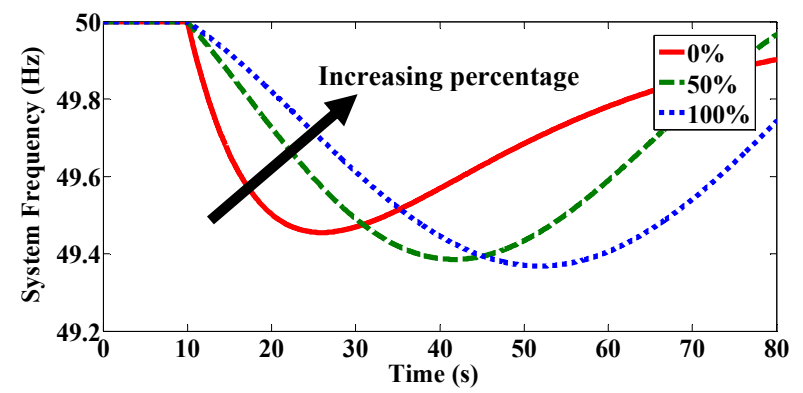

Fig. 12. The Impacts of Percentage of Wind Farms on Frequency Responses.

\section{CONCLUSION}

In response to the ongoing worldwide theme of sustainable development, more and more fossil energy based conventional synchronous generators are being replaced by renewable energy sources for the electricity production in modern power systems. However, some low inertia issues will be brought into the future power systems, which will not be conducive to system frequency stability. This paper aims at improving frequency stability in low inertia power systems using synthetic inertia from DFIG based wind turbines. It is found that measurement noise may help with frequency stability in terms of ROCOF sometimes. Furthermore, when synthetic inertia is applied to GB system model, increasing percentage of wind farms will slow down ROCOF, but decrease frequency nadir. A potential solution to address low frequency nadir issues is to incorporate pitch angle control with synthetic inertia control in order to extract more power from wind turbine during frequency recovery process. In addition, parameter tuning for governor frequency control may need to be performed. It can be eventually verified that the impacts of synthetic inertia from wind turbines will become more significant on system frequency stability in terms of both ROCOF and frequency nadir when more wind farms are being integrated into the future low inertia GB power system.

\section{REFERENCES}

[1] E. W. E. Association, "EU Energy Policy to 2050," 2011. [Online]. Available: $\quad$ http://www.ab.gov.tr/files/ardb/evt/1 avrupa birligi/ 1_9_politikalar/1_9_6_enerji_politikasi/EWEA_EU_Energy_Policy_to_2 050.pdf. [Accessed: 18-May-2016].

[2] D. Energieagentur, "English summary of the dena Grid Study," 2005. [Online]. Available: http://www.deutsche-energie-agentur.de. [Accessed: 18-May-2016].

[3] Department of Energy \& Climate Change, "UK Renewable Energy Roadmap," 2011. [Online]. Available: https://www.gov.uk/government/uploads/system/uploads/attachment_data /file/48128/2167-uk-renewable-energy-roadmap.pdf. [Accessed: 18-May2016].

[4] S. G. Kim and M. Bollen, "The Utilization of synthetic inertia from wind farms and its impact on existing speed governors and system performance," 2013.

[5] F. H. Math Bollen, Integration of Distributed Genration in the Power System, 1st editio. New Jersey, 2011.

[6] F. Gonzalez-longatt, "Effects of the synthetic inertia from wind power on the total system inertia : Simulation study," pp. 389-395, 2012.

[7] J. Zhu, C. D. Booth, G. P. Adam, A. J. Roscoe, and C. G. Bright, "Inertia emulation control strategy for VSC-HVDC transmission systems," IEEE Trans. Power Syst., vol. 28, no. 2, pp. 1277-1287, 2013.

[8] G. Lalor, A. Mullane, and M. O'Malley, "Frequency control and wind turbine technologies," IEEE Trans. Power Syst., vol. 20, no. 4, pp. 19051913, 2005.

[9] M. Wang-Hansen, R. Josefsson, and H. Mehmedovic, "Frequency Controlling Wind Power Modeling of Control Strategies," IEEE Trans. Sustain. Energy, vol. 4, no. 4, pp. 954-959, 2013.

[10] D. Raoofsheibani, "Provision of Primary Control Reserve by DFIGBased Wind Farms in Compliance with ENTSO-E Frequency Grid Codes," pp. 7-12, 2014.

[11] I. Moore and J. Ekanayake, "Frequency response from wind turbines," pp. 1-5, 2009.

[12] I. Erlich and M. Wilch, "Primary frequency control by wind turbines," IEEE Power Energy Soc. Gen. Meet., pp. 1-8, 2010.

[13] F. M. Gonzalez-longatt, "Activation Schemes of Synthetic Inertia Controller for Full Converter Wind Turbine Generators," PowerTech, 2015 IEEE Eindhoven, pp. 1-5, 2015.

[14] K. Knüppel, T, Thuring, P, Kumar, S, Kragelund, MN, Nielsen, R \& André, "Frequency Activated Fast Power Reserve for Wind Power Plant Delivered from Stored Kinetic Energy in the Wind Turbine Inertia," in in 10th International Workshop on Large-Scale Integration of Wind Power into Power Systems as well as on Transmission Networks for Offshore Wind Power Farms, 2011.

[15] A. B. Markus Speckmann, "Provision of Frequency Control by Wind Farms," Germany, 2011.

[16] K. W. de Haan JE, Concha CE, Gibescu M, van Putten J, Doorman GL, "Stabilising system frequency using HVDC between the Continental European, Nordic, and Great Britain systems," Sustain. Energy, Grids Networks, pp. 125-134, 2016.

[17] "G.B. National Grid Status," 2016. [Online]. Available: http://www.gridwatch.templar.co.uk/. [Accessed: 21-Apr-2016].

[18] Richard Smith, "Electricity Ten Year Statement," December, 2012. 